Jurnal Penelitian dan Pengabdian Kepada Masyarakat Bidang ilmu Pendidikan

\title{
Relasi Temporal Antarklausa dalam Kalimat Majemuk Bertingkat pada Koran Kompas
}

\author{
Hasan \\ Program Studi Pendidikan Bahasa dan Sastra Indonesia, STKIP Yapis Dompu \\ E-mail: hasanbsiyapis@gmail.com
}

Article History: Received: 2022-01-11 || Revised: 2022-02-01 || Published: 2022-02-08

Sejarah Artikel : Diterima: 2022-01-11 || Direvisi: 2022-02-01 || Dipublikasi: 2022-02-08

\begin{abstract}
Temporal Relation Between Multi-Clause Compound Sentences in Kompas Newspaper for September-October 2021 Period. This study aims to describe the temporal relation between clauses in compound sentences found in Kompas newspaper. This study uses a descriptive qualitative method because the research only understands and analyzes empirical data objectively. The researcher's target object is what are the markers or conjunctions used in temporal reactions between clauses in compound sentences. How is the distribution of temporal relation markers between clauses in multilevel compound sentences. Whether or not conjunctive sentences or subordinate temporal relations can be combined and sequentially between clauses in a compound sentence can replace each other. The findings of the data in the Kompas newspaper for the period from September to October are temporal markers/starting time, concurrent time, sequential time, and deadline time. The start time is in September 45 and in October 32, the same time is in September 20, the time is consecutively in September 6-October 24, and the deadline is 29.
\end{abstract}

Keywords: Temporal Relations, Compound Sentences, Newspaper.

\begin{abstract}
Abstrak
Relasi Temporal Antarklausa Kalimat Majemuk Bertingkat Pada Koran Kompas Periode September-Oktober Tahun 2021. Penelitian bertujuan untuk mendiskripsikan relasi temporal antarklausa dalam kalimat majemuk yang ditemukan pada koran kompas. Penelitian ini mengunakan metode kualitatif bersifat deskripsi karena penelitian hanya memahami dan menganalisis data empiri secara objektif. Adapan objek sasaran peneliti yaitu apa saja penanda atau konjungsi yang digunakan rekasi temporal antarklausa dalam kalimat majemuk. Bagaimakah distribusi dati penanda relasi temporal antarklausa dalam kalimat majemuk bertingkat. Apakah dapat tidaknya kalimat kata penghubung atau subordinator relasi temporal bersamaan dan berurutaan antarklausa dalam kalimat majemuk dapat saling mengantikan. Hasil temuan data pada koran kompas periode september samapi oktober yaitu penanda temporal/waktu permulaan, waktu bersamaan, waktu berurutan, dan waktu batas akhir. Waktu permulaan di bulan September 45 dan di bulan Oktober 32, waktu bersamaan di september 20, waktu berurutan pada september 6-oktober 24, dan waktu batas akhir 29.
\end{abstract}

Kata kunci: Relasi Temporal, Kalimat Majemuk, Koran.

\section{PENDAHULUAN}

Komunikasi secara umum dapat dikatakan sebagai komunikasi lisan dan komunikasi tulisan. Dalam komunikasi secara lisan seseorang harus memperhatikan kalimat yang diucapkan seperti struktur bahasanya agar tidaK menimbulkan kesalahpahaman bagi pendengar. Begitu pun, dengan bahasa tulisan, sangat perlu memperhatikan tanda baca, dan struktur agar menjadi kalimat yang efektif. Kalimat efektif adalah kalimat yang dengan mudah dipahami oleh pembaca yang membacakan gagasan penulis, media cetak yang ada di Indonesia salah satunya adalah Kompas. Kompas merupakan sebagai sarana komunikasi antara penulis dan pembaca serta menyampaikan informasi kepada publik. Para penulis menyampaikan dan menuangkan tulisanya yang berupa gagasan, pendapat serta realiatas sosial. Penulis yang menulis di Kompas harus memperhatikan ketentuan atau aturan aturan media tersebut. Aturan media tidak keluar dari bahasa-bahasa yang 
wajar dan tidak kasar, kalimat terstruktur agar ide yang disampaikan itu tidak membuat masyarakat pembaca binggung dan tersinggung, oleh karena itulah, media mempunyai editor khusus untuk mengedit supaya terhindar dari hal-hal yang tidak diinginkan oleh masyarakat pembaca.

Kedudukan klausa dalam kalimat merupakan suatu unsur membentuk kalimat, baik kalimat tunggal maupun majemuk. Untuk membuat kalimat majemuk dibutuhkanlah dua klausa. Dua klausa ini mempunyai peranan penting dan selalu hadir bersamaan untuk membentuk kalimat majemuk baik majemuk setara maupun majemuk bertingkat. Dalam kajian ilmu bahasa, klausa itu ada yang namanya klausa terikat dan klausa bebas. Klausa terikat ini selalu membutuhkan klausa lain untuk melengkapinya sedangkan klausa bebas adalah klausa yang bisa berdiri sendiri dan tidak membutuhkan klausa lain. Jadi, pada klausa bebas dan klausa terikat ada penghubung yaitu subordinatif dan koordinatif. Penelitian terdahulu memang sudah ada yang meneliti di dalam media massa, tetapi hanya sebatas aspek semiotik serta kalimat. Adapun kalimat yang diteliti oleh peneliti sebelumnya yaitu kalimat yang elipsis, frase temporal dan klausa kompleks. Untuk itu, perlu dilakukan penelitian lebih lanjut supaya pada aspek lain dapat melihat secara komprehensif terhadap bahasa deskiptif.

Oleh karena itu, penulis masih melihat ada yang kurang, dan perlu diteliti. Penulis berpendapat bahwa bukan hanya makna atau semiotik yang perlu diteliti namun, sintaksis juga perlu diteliti. Penulis menfokuskan analisis dalam kalimat majemuk bertingkat dalam aspek temporal dengan mengangkat judul "Relasi Temporal Antarklausa dalam Kalimat Majemuk Bertingkat". Urgensi dari penelitian ini adalah berangkat dari pandangan, bahwa keutuhan komponen dan ketepatan penghubung merupakan suatu yang diperlukan supaya pembaca dengan mudah memahami isi kalimat dengan baik.

\section{METODE PENELITIAN}

Penelitian ini adalah penelitian yang mengunakan metode kualitatif bersifat deskriptif. Penelitian ini termasuk jenis penelitian diskriptif karena peneliti menganalisis dan memahami data empiris secara objektif terkait dengan objek yang akan diteliti (Sudaryanto, 1993: 63). Metode deskriptif ini digunakan untuk memberikan gambaran, menguraikan, menjelaskan fenomena yang ada. Deskriptif ini mencari, memusatkan, memilih kemudian mengumpulkan dan mengategorisasikan relasi temporal, Objek yang akan dijadikan sasaran dalam penelitian ini yaitu: 1) apa saja penanda yang digunakan untuk menyatakan relasi temporal antarklausa dalam kalimat majemuk bertingkat pada koran "Kompas", 2) bagaimana distribusi dari penanda relasi temporal antarklausa dalam kalimat majemuk bertingkat pada koran "Kompas", 3) apakah dapat tidaknya kata penghubung atau subordinator relasi temporal bersamaan dan berurutan antarklausa dalam kalimat majemuk bertingkat dapat saling mengantikan. Teknik Pengumpulan data yang digunakan adalah teknik simak dan catat. Sedangkan, Teknik Analisis data yang digunakan, yakni 1) teknik urai atau pilah langsung, 2) teknik permutasi atau pembalikan urutan, 3) teknik substitusi atau penggantian, 4) tekni delesi atau pelesapan 5) perluasan atau perluasan (Subroto 1992: 43).

\section{HASIL DAN PEMBAHASAN}

A. Penggunaan Relasi Temporal Batas Waktu Permulaan

Kalimat majemuk bertingkat yang menunjukan waktu permulaan secara sintaksis ditandai dengan subordinasi sedari, dan sejak (Alwi dkk, 2003). Subordinasi (konjungsi) sedari, dan sejak tidak ditemukan semuanya. Adapun data yang ditemukan pada koran Kompas September Oktober 2011 ralasi temporal waktu permulaan dengan konjungsi sejak, bentuk data yang digunakan relasi temporal permulaan sebagai berikut: 
1. Sejak ibu saya bermain kakula, sampai saat ini saya yang memainkan kakulanya tetap sewaan. (SK/Senin/10/0ktober/20111/16/).

2. Sejak menjadi sebagai hakim ad hoe di pengadilan tindak pidana korupsi (Tipikor) Bandung, Ramlan 18 kali mengadili kasus korupsi. (SK/Jumat/14/Oktober/20111/3/).

3. Fenomena itu sudah tampak, sejak karet ekspor dibuka tahun 2005. (8/SK/Selasa/9/2011/17/).

Untuk membuktikan kata konjungsi sebagai subordinator antarklausa dalam kalimat majemuk ini, dapat dilakukan dengan meniadakan konjungsinya.

\section{B. Penggunaan Relasi Temporal Bersamaan pada Koran Kompas}

Hubungan waktu bersamaan menunjukkan hubungan semantis peristiwa dan keadaaan yang terjadi pada dua klausa atau lebih. Dua klausa ini membentuk kalimat majemuk subordinator. Subordinator yang dipakai temporal bersamaan dalam kalimat majemuk yaitu; konjungsi sewaktu, ketika, saat, seraya, sambil, sementara, selagi, tatkalah, dan selama (Alwi dkk, 2003). Adapun data relasi temporal bersamaan dalam kalimat majemuk bertingkat yang ditemukan pada Koran Kompas September-Oktober 2011, yaitu; ketika, saat, sambil, sementara, selama, dan sewaktu.

1. Ketika

a) Namun, kehidupanya yang mapan dibandingkan ketika Ia harus bekerja di kantor. (/30/SK/Senin 12/9/2011/24/).

Pada kalimat majemuk sangatlah penting untuk kehadiran subordinator. Kehadiran konjungtor ketika menggabungkan dua klausa pada kalimat a). Apabila subordinator dihilangkan, kalimat tersebut tidak efektif. Untuk membuktikan hal ini, dilakukan uji coba kalimat mejemuk ini menjadi kalimat tunggal. Untuk lebih jelanya dilihat pada kalimat $\mathrm{a}^{1}$ ) sebagai berikut.

*a1) Namun, kehidupanya yang mapan dibandingkan...ia harus bekerja di kantor

Dari hasil penghilangan subordinator ketika pada kalimat $\mathrm{a}^{1}$ ) di atas tidak membentuk kalimat tunggal yang baik justru kalimat di menjadi rancu. Penanda relasi temporal ketika pada kalimat majemuk di atas sangat mempengaruhi kalimat bila dihilangkan.

2. Saat

a) Kegelisahan Yana mendapat jawaban saat dia bersama beberapa petani bergabung dalam kontak tani nelayan Andalan kabupaten Taksikmalaya menjadi peserta pelatihan sekolah lapang pembelajaran ekologi tanah pada 2001. (14/SK/Kamis/22/2011/16).

b) Sebagai mana diketahui kesepakatan itu ditandatangani saat rapat pleno pengambilangan keputusan tingkat 1 rancangan UU pengganti UU No. 22 tahun 2007 tentang penyelenggara pemilu. (/4/SK/Kamis/22/2011/18).

Pada kalimat majemuk sangatlah penting untuk kehadiran subordinator karena menghubungkan klausa satu dengan klausa lain. Apabila subordinator saat dihilangkan kalimat tersebut tidak mampu mempertahankan keefektifannya. Untuk membuktikan hal ini, dapat diujicobakan kalimat b) menjadi kalimat $b^{1}$ ) sebagai berikut.

${ }^{*} b^{2}$ ) Sebagai mana diketahui kesepakatan itu ditandatangani.....rapat pleno pengambilangan keputusan tingkat 1 rancangan UU pengganti UU No. 22 tahun 2007 tentang penyelenggara pemilu.

3. Sambil

a) Sambil mencari peluang kerja Ali punya banyak waktu untuk belajar dan memperhatikan sang bunda dan kelompok Meseum. (/43/SK/Selasa/20/9/2011/20/). 
b) Begitu suara lembut itu menggema, saya sampai menangis sambil mencuim kain tenun. (/42/SK/Selasa/20/9/2011/16/).

c) Sambil mewawancarai saya, beliau terlihat sibuk mendengar, sambil merapikan berkasberkasnya. (/SK/Sabtu/1/0ktober/2011/25/).

Penempatan konjungtor sambil pada Kalimat a) sangatlah penting. Apabila konjungtor sambil ini dihilangkan atau tidak digunakan pada kalimat a), kalimat tersebut tidak sesuai dengan kaidah kalimat aktif. Ketidakterimaan kalimat tersebut disebabkan predikat ditempatkan di awal kalimat. Untuk lebih jelasnya dapat dilihat pada kalimat $a^{1}$ ) di bawah ini.

* $\mathrm{a}^{1}$ ) .....Mencari peluang kerja Ali punya banyak waktu untuk belajar dan memperhatikan sang bunda dan kelompok Meseum.

4. Sementara

a) Namun karena tidak mendapatkan jawaban dengan alasan masih ditenderkan, sementara kebutuhan peralatan untuk latihan mendesak. (/20/SK/Kamis/22/9/2011/27/).

b) Jerman gemar menabung, sementara Yunani sibuk berkomsumsi. (/49/SK/Selasa/4/10/2011/4/).

Kalimat a) di atas membutuhkan konjungsi untuk menyambungkan klausa lain. Apabila konjungtor sementara ini ditiadakan atau dipaksakan menjadi kalimat tunggal pada kalimat a), kalimat tersebut tidak efektif. Kalimat (a) menjadi kalimat ( $\mathrm{a}^{1}$ ).

${ }^{*} \mathrm{a}^{1}$ ) Namun, karena tidak mendapatkan jawaban dengan alasan masih ditenderkan kebutuhan peralatan untuk latihan mendesak.

5. Selama

a) Selama memimpin Libya, Khadafy tak ada membolehkan ada penguasa lain di luar dirinya. (/SK/Rabu/26/Oktober/2011/7/).

b) Selama karier di kejaksaan, yang bersangutan tidak pernah melakkukan pelanggaran, kata Marwan. (/SK/Rabu/26/0ktober/2011/3/).

Subordinator selama pada kalimat a) kehadirannya sangat menentukan keefektifan kalimat tersebut. Apabila konjungtor selama ini dihilangkan pada kalimat a) dan menempatkan predikat pada awal kalimat, keterangan kalimat tersebut tidak jelas. Untuk lebih jelas dilihat pada kalimat $\mathrm{a}^{1}$ ).

${ }^{*} \mathrm{a}^{1}$ ) .........memimpin Libya, Khadafy tak ada membolehkan ada penguasa lain di luar dirinya.

6. Sewaktu

a) Rindangan juga menghadangannya sewaktu memperluas saluran pembuangan pada kawasan milik Kementerian Kehutanan. (/37/SK/Kamis/15/2011/16/).

b) Ia pun siap jika sewaktu diganti dari jabatan Menpora. (/52/SK/Minggu/18/9/2011/2/).

Konjungtor sewaktu pada kalimat a) dan b) di atas pada awalnya merupakan kalimat mejemuk bertingkat. Kalimat majemuk bertingkat ditandai dengan relasi temporal sewaktu ini apabila dihilangkan subordinasi sewaktu kalimat tersebut tetap menjadi kalimat aktif. Untuk membuktikan dapat dilihat di bawah ini.

${ }^{*} \mathrm{a}^{1}$ ) Rindangan juga menghadangannya.......memperluas saluran pembuangan pada kawasan milik Kementerian Kehutanan.

${ }^{*} b^{1}$ ) Ia pun siap jika...... diganti dari jabatan Menpora. 
C. Penggunaan Relasi Temporal Batas Akhir Pada Koran Kompas

Relasi waktu batas akhir dipakai untuk menyatakan ujung suatu proses. Relasi waktu batas akhir ini secara sintaksis lazimnya dipakai sebagai subordinasi (konjungsi) sampai, dan sehingga. Secara teori dapat dikakatan bahwa waktu batas akhir dipakai subordinasi sehingga dan sampai (Alwi dkk, 2003). Data ditemukan dikoran Kompas September-Oktober 2011 relasi temporal batas akhir yaitu; sehingga, sampai.

1. Sehingga

a) Akibat atvokasi menjadi tak independen sehingga menghambat penegak hukum.

b) Harga gabah tetap harus sesuai ketentuan pemerintah, sehingga petani tak rugi, kata Ambara. (/6/SK/Senin/19/9/2021/24/).

Apabila Subordinator sehingga yang menjadi relasi temporal pada kalimat a) dihilangkan kalimat tersebut tidak efektif. Konjungtor sehingga sangat menentukan kefektifan kalimat tersebut karena kata sehingga menjadi penghubung klausa dengan klausa lain pada kalimat b). Ketidakefektifan kalimat dapat dilihat pada kalimat $a^{1}$ ) sebagai di bawah ini.

${ }^{*} a^{1}$ ) Harga gabah tetap harus sesuai ketentuan pemerintah,....petani tak rugi, kata Ambara.

2. Sampai

a) Ali harus mengelolah museum tenun ikat itu, seorang diri mulai dari menyapu, mencabut rumput, menghias taman sampai menambah dan memajang koleksi Museum. (/10/SK/Selasa/20/9/2021/16/).

b) Saya berharap bahu membahu memperjuankan bangsa palestina, sampai mereka meraih kemerdekaan, kata Ahmad Dinejad. (/Rabu/5/0ktober/2021/9/).

Konjungtor sampai pada kalimat b) ini dapat dilakukan dengan cara meniadakan konjungsinya. Apabila subordinator sampai dihilangkan, pada kalimat tersebut memungkinkan klausa pertama dengan klausa dua tidak kohesi. Untuk melihat ketidakkohesian kalimat tersebut dapat dilihat kalimat $\mathrm{b}^{1}$ ) sebagai berikut.

${ }^{*} b^{1}$ ) Saya berharap bahu membahu memperjuankan bangsa palestina,..., mereka meraih kemerdekaan, kata Ahmad Dinejad.

\section{SIMPULAN DAN SARAN}

\section{A. Simpulan}

Berdasarkan hasil penelitian yang telah dilakukan, maka dapat disimpulkan bahwa a) Penanda relasi temporal permulaan yang ditemukan adalah subordinasi; sejak. Penanda relasi bersamaan yang ditemukan subordinasi; saat, ketika, sementara, selama, sambil, selagi, dan sewaktu. Pada relasi berurutan oleh peneliti ditemukan subordinasi; setelah, sebelum, seusai, begitu, sehabis, sesudah. Pada relasi temporal batas akhir ditemukan subordinasi; sampai, sehingga, b) Penanda relasi temporal yang mendominasi pada koran Kompas adalah subordinator saat yang merupakan penanda dari relasi temporal bersamaan, dan c) Tidak semua relasi temporal pada kalimat mejemuk bertingkat selalu bisa berdistribusi pada awal kalimat dan tengah kalimat.

\section{B. Saran}

Pengunaan kata konjungsi yang tepat pada kalimat majemuk merupakan suatu keharusan. Penulis harus memperhatikan secara cermat untuk menempatkan konjungtornya. Kualitas dan tidaknya gagasan yang kita tuangkan baik berupa tulisan maupun lisan tergantung pada penggunaan kata konjungsi yang tepat. Oleh karena itu, seorang penulis maupun pembicara harus tepat menempati konjungsinya. 


\section{DAFTAR RUJUKAN}

Abdul Chaer. (2017). Linguistik Umum. Jakarta: Rineka Cipta.

Barbara Meisterenst. (2010). The Syntax of Hou In Temporal Phrases in Han Period Chinese. JRAS, Series 3, 20, 4 (2010), pp. 503-522C- doi: 10.1017/S13561863100000258 the Royal Asiatic Society.

Burhan Bungin. (2015). Konstruksi Sosial Media Massa. Jakarta: Kencana Prenada Media

Gregory M. Kobele. (2005). “Generating Copies: An Investigation into Structural Identity in Language Grammar". University of California; Los Angeles. Features Moving Madly: A Formal Perspective on Feature Movement in the Minimalist Program. Research on Language and Compotation, 3(4):391-410. 2005.

Harimurti Kridalaksana. (2001). Kamus Linguistik (Edisi Ketiga). Jakarta: Gramedia Pustaka Utama.

Hasan Alwi, dkk. (2016). Tata Bahasa Baku Bahasa Indonesia. Jakarta: Pusat Bahasa dan Balai Pustaka.

Ida Bagus Putrayasa. (2006). Tata Kalimat Bahasa Indonesia. Bandung; Refika Aditama.

Karlos Arregi. (2010). Ellipsis in Split Questions. Received: 5 June 2007/Accepted: 23 July 2009/ Published Online: 10 August 2010. (C) Springer Science+Business Media B.V. 2010.

Maryam, Ernawati (2013) Analisis Klausa Kompleks Dalam Novel No Greater Love Karya Danielle Steel (Kajian Tata Bahasa Fungsional). Diploma thesis, Universitas Komputer Indonesia. Official URL: http://elib.unikom.ac.id/gdl.php?mod=browse\&op=rea...

Romli, Khomsahrial. (2016). Komunikasi Massa. Jakarta: PT Grasindo

Taufik, Erwin, \& Husnul Khatimah. (2020). Pengembangan Perangkat Pembelajaran Model CIRC pada Mata Kuliah Apresiasi Sastra "Mantra Mbojo" untuk Melatih Kemampuan Berpikir Kreatif Mahasiswa. JIIP - Jurnal Ilmiah Ilmu Pendidikan,3(3), 635-641. Retrieved from http://jiip.stkipyapisdompu.ac.id/jiip/index.php/IIIP/article/view/171

Yulianti, E., \& Taufik, T. (2020). Studi Perbandingan Eksistensi Alam Pada Novel Tanah Baru Tanah Air Kedua Karya Nh. Dini Dan Sri Rinjani Karya Eva Nourma (Tinjauan Ekologi Sastra). Ainara Journal (Jurnal Penelitian Dan PKM Bidang Ilmu Pendidikan), 1(2), 44-55. https://doi.org/10.54371/ainj.v1i2.13 